\title{
PRODUÇÃO DE SILAGEM COM DIFERENTES POPULAÇÕES DE MILHO PARA A AGRICULTURA FAMILIAR NO MUNICÍPIO DE COLATINA, ESPÍRITO SANTO
}

\author{
Vinicius de Souza Oliveira ${ }^{1}$ \\ Luciene Lignani Bitencourt ${ }^{2}$ \\ Ana Paula Candido Gabriel Berilli ${ }^{2}$ \\ Eline Paula Figueira Cazaroti ${ }^{2}$ \\ Eduardo Varnier ${ }^{2}$ \\ Daniela Milanez Spalenza ${ }^{2}$ \\ Diego Pereira do Couto ${ }^{2}$ \\ Sarah Helmer de Souza ${ }^{2}$ \\ Nadhyla Pião Felberg ${ }^{2}$ \\ Jhuilker Jhunior Oliveira Gomes ${ }^{2}$
}

\section{RESUMO}

A ensilagem é uma das práticas de conservação de forragem utilizada para melhorar a alimentação do rebanho e minimizar os efeitos da escassez de pastagens no período de estiagem. Assim, é de fundamental importância que se tenha à disposição do produtor materiais genéticos com melhor qualidade específica para cada região. O objetivo desse trabalho foi avaliar o potencial de populações de milho (Zea mays L.) do banco de germoplasma do IFES Campus Itapina para produção de silagem, com base em suas características agronômicas e bromatológicas. Foram avaliadas populações crioulas, no delineamento em blocos casualizados com quatro repetições e nove tratamentos. Plantas dessas mesmas populações foram colhidas para ensilagem quando os grãos se encontraram no estádio $1 / 3$ da linha do leite. A silagem foi confeccionada em baldes plásticos com capacidade de 15 litros, com abertura após 90 dias para avaliação das características bromatológicas. Foram encontradas diferenças significativas para todas as características avaliadas pelo teste de $\mathrm{F}$ a $5 \%$ de probabilidade. Considerando as características agronômicas, as populações Piranão 14 e Cimmyt 14 se destacaram para os quesitos produtividade de grãos, participação de espigas, e altura de plantas. A utilização do parâmetro 1/3 da linha do leite como indicador de ponto de colheita promoveu o uso de materiais de teor de umidade bastante variáveis e, em média, abaixo do ótimo. Na avaliação da composição bromatológica das silagens, o genótipo Encapa se sobressaiu apresentando teores de proteína bruta $(\mathrm{PB})$ e amido superiores aos demais. $\mathrm{O} \mathrm{pH}$ das silagens foi, em média, 3,7, indicando fermentação adequada.

\footnotetext{
${ }^{1}$ Universidade Federal do Espírito Santo, Centro Universitário Norte do Espírito Santo, São Mateus-Espírito Santo. Autor para correspondência: souzaoliveiravini@gmail.com

${ }^{2}$ Instituto Federal do Espírito Santo, Ifes Campus Itapina, Colatina-Espírito Santo.
} 
Palavras-chave: Zea mays. Conservação de alimento. Qualidade da silagem.

\title{
PRODUCTION OF SILAGE WITH DIFFERENT POPULATIONS OF CORN FOR A FAMILY AGRICULTURE NO MUNICIPALITY OF COLATINA, ESPÍRITO SANTO
}

\begin{abstract}
Silage is one of the forage conservation practices used to improve herd feeding and to minimize the effects of pasture scarcity during the dry season. Thus, it is of fundamental importance that genetic material with better quality specific to each region is available to the producer. The objective of this work was to evaluate the potential of corn (Zea mays L.) populations of the germplasm bank of the IFES Campus Itapina for silage production, based on their agronomic and bromatological characteristics. Creole populations were evaluated in a randomized complete block design with four replicates and nine treatments. Plants of these same populations were harvested for ensiling when the grains were found in the $1 / 3$ stage of the milk line. The silage was made in plastic buckets with capacity of 15 liters, with opening after 90 days to evaluate the bromatological characteristics. Significant differences were found for all the characteristics evaluated by the $5 \%$ probability $\mathrm{F}$ test. Considering the agronomic characteristics, the populations Piranão 14 and Cimmyt 14 stood out for grain yield, spike participation, and plant height. The use of parameter 1/3 of the milk line as a point of harvest indicator promoted the use of materials with a very variable moisture content and, on average, below the optimum. In the evaluation of the bromatological composition of the silages, the genotype Encapa stood out presenting higher levels of crude protein $(\mathrm{PB})$ and starch. The $\mathrm{pH}$ of the silages was, on average, 3.7 , indicating adequate fermentation.
\end{abstract}

Keywords: Zea mays. Food preservation. Quality silage.

\section{INTRODUÇÃO}

O Estado do Espírito Santo possui uma estrutura agrária em que 92\% dos estabelecimentos contém até 100 hectares, sendo que deste total cerca de $83 \%$ possui área abaixo de 50 hectares. Desta forma é evidente o grande número de pequenas propriedades, caracterizando uma agricultura familiar que pratica a atividade com pouco investimento e pouca tecnificação, refletindo em baixos índices de produtividade (PEDEAG, 2008). 
O Estado é caracterizado por apresentar duas estações definidas ao longo do ano: uma seca e outra chuvosa (INCAPER, 2017), ocasionando períodos de escassez e abundância de forragens para alimentação animal. A ensilagem é uma das práticas de conservação de alimentos importante no contexto produtivo da pecuária, pois tal alimento minimiza os efeitos da escassez de pastagens, sendo primordial para a dieta constante dos animais (VIEIRA et al., 2013; NEUMANN, 2017).

Tradicionalmente, o material mais utilizado para ensilagem é a planta de milho (Zea mays L.), devido ao alto rendimento de massa verde por hectare e boa aceitação pelos animais (ALMEIDA FILHO et al., 1999). No entanto, dentre os diversos fatores que interferem na quantidade e qualidade da silagem produzida destaca-se o genótipo de milho utilizado (JAREMTCHUCK et al., 2005; ROSA et al., 2004).

O uso de cultivares de milho mais produtivas e adaptadas às condições locais tem sido apontado como responsável pelos maiores ganhos obtidos em produtividade (JAREMTCHUCK et al., 2005). A inexistência de dados regionais pertinentes ao desempenho agronômico produtivo e valor nutritivo dos diversos materiais genéticos existentes, torna-se um empecilho para uma melhor programação da escolha dos genótipos de milho destinados para a produção de silagem no Estado (ROSA et al., 2004).

De modo geral, pesquisas de comparação entre populações e cultivares são fundamentais para o avanço dos programas de melhoramento genético e importantes na recomendação a técnicos e produtores sobre o material destinado à produção de silagem com melhor relação produção/valor nutritivo.

Portanto, a caracterização agronômica e bromatológica dos materiais genéticos disponíveis é de fundamental importância para se obter alta produção de silagem com elevado valor nutritivo. A identificação de plantas mais adaptadas às condições em que serão cultivadas contribuirá para maiores rendimentos da cultura do milho, ressaltando que, além da genética, a produção é influenciada, entre outros fatores, pela qualidade das sementes, época de semeadura, população de plantas, preparo, correção e adubação do solo, controle de plantas daninhas, pragas e doenças, irrigação, entre outros (ALMEIDA FILHO et al., 1999).

Nesse sentido, o objetivo nesse trabalho foi avaliar o potencial de populações de milho que fazem parte do germoplasma do Ifes Campus Itapina para produção de silagem, com base em suas Revista Ifes Ciência, v.4, n.2, 2018 - Instituto Federal do Espírito Santo 
características agronômicas e bromatológicas, bem como identificar aquelas mais adaptadas às condições edafoclimáticas da região.

\section{MATERIAIS E MÉTODOS}

O experimento foi conduzido no campo experimental do Instituto Federal do Espírito Santo Campus Itapina, em Colatina, município localizado no Norte do estado do Espírito Santo e situado a $19^{\circ} 32^{\prime} 22^{\prime \prime}$ de latitude Sul e 40 37' 50" de longitude Oeste e altitude de $71 \mathrm{~m}$. O clima da região, segundo a classificação de Köppen, é do tipo Tropical Aw. A precipitação média anual de $900 \mathrm{~mm}$ e temperatura média anual entre $25^{\circ} \mathrm{C}$ (BUSATO, 2010). Durante o período de março a junho de 2016 a precipitação, temperatura mínima, máxima e média registradas na área de condução do experimento estão apresentados na Tabela 1.

Tabela 1 - Dados meteorológicos registrados durante o período de condução do experimento.

\begin{tabular}{c|c|c|ccc}
\hline Mês/Ano & $\begin{array}{c}\text { Dias de } \\
\text { chuva }\end{array}$ & $\begin{array}{c}\text { Chuva } \\
(\mathbf{m m})\end{array}$ & Máx. & Mín. & Média \\
\hline Março/2016 & 0 & 0 & 35,7 & 22,2 & 28,1 \\
Abril/2016 & 5 & 19,2 & 34 & 21,2 & 27 \\
Maio/2016 & 4 & 36,4 & 31,2 & 19,2 & 24,2 \\
Junho/2016 & 5 & 35,2 & 28,4 & 16,7 & 21,6 \\
\hline
\end{tabular}

Fonte: Próprios autores

O solo da região e classificado como Latossolo vermelho distrófico. Para o preparo da área foi usado o sistema convencional, com uma aração e uma gradagem. A adubação foi feita conforme a análise química do solo na camada de 0-20 cm (Tabela 2). Onde utilizou-se $250 \mathrm{~kg}$ de N-P-K de formulação 4-14-7 na semeadura e $250 \mathrm{~kg}$ de ureia aos 45 dias após o plantio.

Tabela 2 - Características químicas do solo na camada de 0-20 cm.

\begin{tabular}{|c|c|c|c|c|c|c|c|c|c|}
\hline \multirow[t]{2}{*}{$\mathbf{p H}$} & M.O & $\mathbf{P}$ & $\mathbf{K}$ & $\mathbf{C a}$ & Mg & $\mathbf{A l}$ & $\mathrm{H}+\mathrm{Al}$ & S.B & \multirow[t]{2}{*}{$\mathbf{V}$} \\
\hline & $\mathrm{g} / \mathrm{dm}^{3}$ & \multicolumn{2}{|c|}{$\mathrm{mg} / \mathrm{dm}^{3}$} & \multicolumn{5}{|c|}{ Mmloc/dm ${ }^{3}$} & \\
\hline 5,4 & 19,4 & 12 & 95 & 33,7 & 10,2 & 1,4 & 19,1 & 46,3 & 70,8 \\
\hline
\end{tabular}

Fonte: Próprios autores

O delineamento experimental utilizado foi em blocos casualizados, com quatro repetições e nove tratamentos. As parcelas foram constituídas por fileiras de cinco metros, espaçadas entre si por 1,0 
metro, apresentando um espaçamento, entre as plantas, de 0,20 m, com um total de 25 plantas por parcela, após o desbaste. Os tratamentos foram constituídos de nove genótipos de milho oriundos de diferentes regiões do estado do Espírito Santo e de outras Instituições do País, conforme apresentado na tabela 3 .

Tabela 3 - Genótipos de milho (Zea mays L.) avaliados, Classificação do grão, Tipo de polinização e Origem.

\begin{tabular}{c|c|c|c}
\hline Genótipo & $\begin{array}{c}\text { Classificação } \\
\text { do grão }\end{array}$ & $\begin{array}{c}\text { Tipo de } \\
\text { polinização }\end{array}$ & Origem (produtor/Instituição) \\
\hline Crioulo (Aliança) & Dentado & Aberta & Muqui - ES (Nélio Souza/Fazenda Aliança) \\
Crioulo (Perin) & Dentado & Aberta & Muqui- ES (Péricles Bettero / Fazenda Cupido \\
Crioulo (ES 001) & Semiduro & Aberta & Laranja da Terra - ES \\
Fortaleza & Dentado & Aberta & Muqui - ES (Cláudio Candido/Sítio \\
Cimmyt 11 & Flint (duro) & Aberta & Universidade Estadual do Norte Fluminense \\
Encapa 203 & Flint (duro) & Aberta & INCAPER \\
Piranão 14 & Dentado & Aberta & Universidade Estadual do Norte Fluminense \\
Piranão 11 & Dentado & Aberta & Universidade Estadual do Norte Fluminense \\
Cimmyt 14 & Flint (Duro) & Aberta & Universidade Estadual do Norte Fluminense \\
\hline
\end{tabular}

Fonte: Próprios autores

As seguintes características agronômicas foram avaliadas: Idade da planta em dias (Ida), correspondente aos dias entre a emergência das plantas até o corte para ensilagem; altura de plantas (Alp), medindo-se do nível do solo até a inserção da última folha, em metros; altura da espiga (Ale) medida do nível do solo até o nó de inserção da espiga superior no colmo, em metros; número de plantas acamadas (Npa), contagem das plantas com ângulo superior a $20^{\circ}$; número de plantas quebradas (Npq), contagem das plantas quebradas abaixo da espiga ou panícula; número espigas (Nes), contagem do número total de espigas colhidas ; produtividade de grãos (Prodg), valor estimado pelo peso de grãos em T/ha; empalhamento (Emp), número de espigas mal empalhadas, as quais deixam grãos expostos; número de espigas doentes (Ned), contagem total das espigas que manifestaram sintomas de doenças e número de espigas atacadas por pragas (Neap), contagem do número total de espigas brocadas. 
A colheita foi efetuada, de acordo com o ciclo de cada população, quando os grãos se encontravam no estágio de $1 / 3$ da linha do leite, normalmente recomendado para início da colheita (D' OLIVEIRA; OLIVEIRA, 2014) e realizada manualmente, com o corte a 15 centímetros acima do nível do solo. Em seguida, as plantas foram picadas em ensiladeira. O ponto de regulagem da máquina foi determinado para que não passasse nenhum grão inteiro pelos rolos.

A ensilagem foi realizada em mini-silos, constituídos por baldes plásticos com capacidade de 15 litros, sendo a compactação realizada através de pisoteio, posteriormente foram cobertos com lona preta e uma camada de areia grossa. No momento da abertura dos mini-silos, realizada aos 90 dias após o fechamento, as camadas superiores, inferiores e laterais de cada mini-silo foram desprezadas.

Duas amostras foram obtidas, sendo uma utilizada para determinar o $\mathrm{pH}$, com pontenciômetro digital, após diluição e processamento por um minuto em liquidificador de $25 \mathrm{~g}$ de silagem diluída em $225 \mathrm{~mL}$ de água destilada. Outra amostra foi utilizada para análise bromatológica. Após descongelamento, essas amostras foram pré-secas em estufa ventilada por 72 horas a $55^{\circ} \mathrm{C}$, trituradas em peneira de $1 \mathrm{~mm}$ em moinho do tipo Thomas-Willey, e uma sub-amostra foi desidratada a $100^{\circ} \mathrm{C}$ por 24 horas para determinação do teor de MS.

Para as determinações da fibra em detergente neutro (FDN) foi utilizada a metodologia proposta por Van Soest et al. (1991) com $\alpha$-amilase termoestável e uréia a 8 molar, a fim de reduzir a contaminação do amido e facilitar a filtragem. $\mathrm{O}$ teor de amido foi determinado pelo método de Back Knudsen modificado (HALL, 2009). Para porcentagem de proteína bruta (PB) foi avaliado o teor de nitrogênio, utilizando-se o aparelho de destilação a vapor micro-Kjedahl conforme AOAC International (2012).

Os dados foram submetidos a análise de variância. As médias foram comparadas pelo teste de Tukey a 5\% de probabilidade, utilizando o pacote estatístico Assistat versão 7.7 beta.

\section{RESULTADOS E DISCUSSÃO}

Após realização da análise de variância, as médias dos tratamentos foram submetidas ao teste estatístico. Constatou-se que houve diferenças significativas pelo teste de Tukey a 5\% de probabilidade para todas as características analisadas tanto agronômicas quando bromatológicas, indicando que há variabilidade entre os genótipos. Esses resultados são importantes por mostrar que 
os genótipos analisados se comportaram de maneira diferente para quase todas as características avaliadas.

Na tabela 4 são apresentados os dados médios das características agronômicas dos genótipos avaliados. Observa-se que, de acordo com a classificação de Scapim et al. (1995), elaborada levando-se em consideração a cultura estudada e a natureza das características avaliadas, os coeficientes de variação da maioria dos caracteres foram considerados médios, demonstrando boa precisão na condução dos ensaios.

Tabela 4 - Valores médios, média geral e coeficiente de variação (CV) das características agronômicas avaliadas.

\begin{tabular}{l|c|c|c|c|c|c|c|c|c|c}
\hline Genótipo & Ida & Alp & Ale & Npa & Npq & Nes & Prodg & Emp & Neap & Ned \\
\hline Encapa & 90 & $2,50 \mathrm{bc}$ & $1,44 \mathrm{bc}$ & $0 \mathrm{c}$ & $1 \mathrm{ab}$ & $19 \mathrm{def}$ & $4,75 \mathrm{abc}$ & $1 \mathrm{c}$ & $1 \mathrm{~d}$ & $1 \mathrm{c}$ \\
Perin & 94 & $2,96 \mathrm{a}$ & $1,84 \mathrm{a}$ & $2 \mathrm{a}$ & $1 \mathrm{ab}$ & $18 \mathrm{ef}$ & $5,63 \mathrm{abc}$ & $1 \mathrm{c}$ & $2 \mathrm{~cd}$ & $2 \mathrm{c}$ \\
Cimmyt 11 & 94 & $2,07 \mathrm{f}$ & $1,25 \mathrm{~d}$ & $0 \mathrm{c}$ & $2 \mathrm{a}$ & $23 \mathrm{cde}$ & $4,47 \mathrm{bc}$ & $4 \mathrm{~b}$ & $4 \mathrm{bc}$ & $3 \mathrm{bc}$ \\
Aliança & 94 & $2,60 \mathrm{bc}$ & $1,48 \mathrm{~b}$ & $1 \mathrm{ab}$ & $0 \mathrm{~b}$ & $24 \mathrm{~cd}$ & $6,55 \mathrm{ab}$ & $2 \mathrm{c}$ & $1 \mathrm{~d}$ & $1 \mathrm{c}$ \\
Fortaleza & 94 & $2,67 \mathrm{~b}$ & $1,53 \mathrm{~b}$ & $1 \mathrm{ab}$ & $1 \mathrm{ab}$ & $12 \mathrm{~g}$ & $3,18 \mathrm{c}$ & $0 \mathrm{c}$ & $1 \mathrm{~d}$ & $2 \mathrm{c}$ \\
ES 001 & 90 & $2,13 \mathrm{ef}$ & $1,19 \mathrm{~d}$ & $0 \mathrm{c}$ & $2 \mathrm{a}$ & $16 \mathrm{fg}$ & $3,27 \mathrm{c}$ & $1 \mathrm{c}$ & $0 \mathrm{~d}$ & $1 \mathrm{c}$ \\
Piranão 14 & 94 & $2,43 \mathrm{~cd}$ & $1,45 \mathrm{bc}$ & $0 \mathrm{c}$ & $2 \mathrm{a}$ & $33 \mathrm{ab}$ & $5,74 \mathrm{abc}$ & $1 \mathrm{c}$ & $6 \mathrm{ab}$ & $5 \mathrm{ab}$ \\
Piranão 11 & 94 & $2,47 \mathrm{bcd}$ & $1,46 \mathrm{bc}$ & $1 \mathrm{ab}$ & $1 \mathrm{ab}$ & $34 \mathrm{a}$ & $3,21 \mathrm{c}$ & $1 \mathrm{c}$ & $5 \mathrm{ab}$ & $3 \mathrm{bc}$ \\
Cimmyt 14 & 94 & $2,30 \mathrm{de}$ & $1,28 \mathrm{~cd}$ & $1 \mathrm{ab}$ & $1 \mathrm{ab}$ & $28 \mathrm{bc}$ & $5,22 \mathrm{abc}$ & $7 \mathrm{a}$ & $7 \mathrm{a}$ & $6 \mathrm{a}$ \\
\hline \multicolumn{1}{c}{ Média G } & & $\mathbf{2 , 4 5}$ & $\mathbf{1 , 4 4}$ & $\mathbf{0}$ & $\mathbf{1}$ & $\mathbf{2 2 , 7 7}$ & $\mathbf{4 , 6 7}$ & $\mathbf{2}$ & $\mathbf{2 , 8 6}$ & $\mathbf{2 , 5 8}$ \\
\multicolumn{1}{c}{ CV \% } & & $\mathbf{5 , 7 4}$ & $\mathbf{8 , 9 6}$ & $\mathbf{1 2 6 , 6 4}$ & $\mathbf{1 0 4 , 2 6}$ & $\mathbf{1 6 , 0 9}$ & $\mathbf{1 9}$ & $\mathbf{5 9 , 9 7}$ & $\mathbf{5 9 , 5 2}$ & $\mathbf{7 0 , 4 3}$
\end{tabular}

${ }^{1}$ Idade da planta (Ida), Altura de plantas (Alp), Altura de espiga (Ale), Número de plantas acamadas (Npa), Número de plantas quebradas (Npq), Número de espigas (Nes), Produtividade de grãos (Prodg), Empalhamento (Emp), Número de espigas atacadas por pragas (Neap), Número de espigas doentes (Ned).

${ }^{2}$ Médias seguidas de mesma letra não diferem entre si pelo teste de Tukey a 5\% de probabilidade.

Fonte: Próprios autores

No entanto, as características número de plantas acamadas (Npa), número de plantas quebradas $(\mathrm{Npq})$ e número de espiga doente (Ned) apresentaram valores de coeficiente de variação muito altos. Daros et al. (2004), Berilli et al. (2011), Berilli et al. (2013), Santos et al. (2008), avaliando populações de milho também encontraram valores considerados muito altos de coeficiente de variação para estas mesmas características. 
A idade das plantas desde a semeadura até a colheita ficou em 90 dias para os genótipos Encapa e ES 001, enquanto os demais genótipos apresentaram ponto de colheita estabelecido com $1 / 3$ da linha do leite aos 94 dias. Para Paziani et al. (2009), os genótipos de milho que apresentam ciclos mais precoces são favoráveis para a produção de silagem por serem mais produtivos em massa verde, massa seca, grãos na espiga e matéria seca digestível.

Quanto à altura das plantas, houve diferença significativa entre os genótipos avaliados (Tabela 4). O genótipo Cimmyt 11 foi o que apresentou a menor altura de planta, com 2,07 metros, enquanto o genótipo Perin foi o que apresentou maior porte com 2,96 metros. Com exceção do genótipo Perin, verificou-se que todos os outros genótipos avaliados caracterizam-se como materiais de porte médio (2,80 $\mathrm{m}$ a 2,20 m) a baixo (menor que 2,20 m), sendo essa característica dependente não só da genética da planta como também das condições do ambiente e práticas de manejo (PINTO, 2010).

Plantas de porte baixo poderiam reduzir as perdas por acamamento e quebramento e o auto sombreamento das folhas (JAREMTCHUK et al., 2005). Aliado a essas vantagens, permitiriam a redução do espaçamento entre linhas de semeadura e o acréscimo do número de plantas por unidade de área (maior densidade populacional). Dessa forma, plantas com porte reduzido poderiam contribuir para o aumento do potencial de rendimento da cultura, além de facilitarem a execução das operações de cultivo e colheita mecanizados (BERILLI et al., 2013).

Para altura de espiga os genótipos Perin e ES 001 apresentaram os dois extremos com 1,84 metros e 1,19 metros, respectivamente. Repke (2012), salientam que a altura da espiga é um dos fatores que contribuem para o acamamento das plantas, pois quanto mais altas mais suscetíveis a este problema, uma vez que alturas elevadas de planta e inserção de espigas, podem mudar o centro de gravidade da planta.

As médias encontradas nesse trabalho revelam que o genótipo Perin, teve as maiores médias para altura de plantas e para altura de espigas e também apresentaram as maiores médias para a característica planta acamada (Tabela 4), corroborando assim com as conclusões de Repke et al. (2012). De modo geral, todos os genótipos avaliados apresentaram resultados médios de plantas acamadas e quebradas baixos.

Em relação ao número de espigas verificou-se que houve diferença significativa entre os genótipos avaliados, Piranão 11 e Piranão 14 apresentaram maior número total de espigas colhidas (34 e 33, 
respectivamente), e o Fortaleza o menor número (12). Para Jaremtchuk et al. (2005), o número de espigas por planta é um componente do rendimento importante na produtividade do milho. Ainda segundo este autor, a utilização de plantas prolíficas, ou seja, com maior número de espigas por planta, poderia potencializar o rendimento de grãos por unidade de área pela maior quantidade de espigas por unidade de área, sendo interessante pelo fato de contribuir para a qualidade superior da forragem e, posteriormente, da silagem.

Para a característica produtividade de grãos o genótipo que mais se destacou foi o Aliança com estimativa de 6,55 T/ha, enquanto o genótipo Fortaleza apresentou piores rendimentos, estimado em 3,18 t/ha. De modo geral, a média observada para este quesito foi de 4,67 t/ha ficando acima das médias de produtividade do estado do Espírito Santo com 2,83 T/ha, respectivamente (CONAB, 2017). Segundo Lupatini et al. (2004), a quantidade de grãos interfere no valor energético da silagem, refletindo no desempenho do animal. Desta forma uma maior produtividade de grãos favorece a produção de silagem de melhor qualidade.

As características de empalhamento, número de espigas atacadas por praga e número de espigas doentes são de grande importância na escolha de um genótipo de milho para produção de silagem. Estas características mesmo sendo qualitativas influenciam diretamente na produtividade, pois o mal empalhamento faz com que as espigas fiquem vulneráveis a uma maior incidência de pragas, destruindo os grãos, diminuindo o peso e a utilização das espigas, pois a palha tem como função proteger e gerar resistência aos fatores bióticos e abióticos (DAROS et al., 2004).

Espigas com características de grão dentados, as quais são mais utilizadas para o processo de ensilagem, apresentam endosperma mais macios as tornando mais suscetíveis ao ataque de pragas (BERILLI et al., 2013). Este fator provavelmente explique um maior grau de espigas atacadas nos genótipos Piranão 11 e Piranão 14, já que apresentam endosperma macio (Tabelas 3 e 4).

Na tabela 5 estão apresentadas as características bromatológicas avaliadas. Os genótipos analisados apresentaram teores de matéria seca entre $24 \%$ e $31 \%$, ficando fora do recomendado por Pinto et al. (2010) que seria de 32 a 35\%, apesar da colheita ter sido feita quando os genótipos apresentaram 1/3 da linha do leite, estádio normalmente recomendado para início da colheita (D' OLIVEIRA e OLIVEIRA, 2014). Resultados similares foram encontrados por Jaremtchuk et al. (2005), constatando que o emprego deste parâmetro não é satisfatório pois promove quantidade de umidade bem variados. 
Silagens muito úmidas favorecem a fermentação clostrídica e a produção de efluentes, reduzindo o valor nutricional da silagem. Por outro lado, silagens muito secas diminui a qualidade da fibra, além de causando complicação na colheita e na compactação do silo (D' OLIVEIRA e OLIVEIRA, 2014).

Tabela 5 - Valores médios, média geral e coeficiente de variação (CV) das características bromatológicas avaliadas.

\begin{tabular}{l|c|c|c|c|c}
\hline Genótipo & MS\% & pH & FDN\% & PB\% & Amido\% \\
\hline Encapa & 26 & $3,7 \mathrm{ac}$ & $55,4 \mathrm{ab}$ & $12,6 \mathrm{a}$ & $29,6 \mathrm{a}$ \\
Perin & 24 & $3,7 \mathrm{ab}$ & $56,1 \mathrm{ab}$ & $10,8 \mathrm{ab}$ & $21,9 \mathrm{~b}$ \\
Cimmyt 11 & 25 & $3,8 \mathrm{a}$ & $55,8 \mathrm{ab}$ & $10,7 \mathrm{~b}$ & $14,2 \mathrm{c}$ \\
Aliança & 30 & $3,7 \mathrm{bc}$ & $48,1 \mathrm{~b}$ & $10,8 \mathrm{ab}$ & $20,8 \mathrm{~b}$ \\
Fortaleza & 25 & $3,7 \mathrm{ab}$ & $56,8 \mathrm{ab}$ & $10,9 \mathrm{ab}$ & $16,5 \mathrm{bc}$ \\
ES 001 & 26 & $3,8 \mathrm{a}$ & $58,6 \mathrm{a}$ & $11,9 \mathrm{ab}$ & $20,7 \mathrm{~b}$ \\
Piranão 14 & 25 & $3,6 \mathrm{c}$ & $55,9 \mathrm{ab}$ & $10,8 \mathrm{ab}$ & $20,3 \mathrm{~b}$ \\
Piranão 11 & 31 & $3,7 \mathrm{ab}$ & $55,0 \mathrm{ab}$ & $10,4 \mathrm{~b}$ & $21,4 \mathrm{~b}$ \\
Cimmyt 14 & 24 & $3,7 \mathrm{ab}$ & $55,6 \mathrm{ab}$ & $10,7 \mathrm{~b}$ & $17,1 \mathrm{bc}$ \\
\hline \multicolumn{1}{c}{ Média G } & & $\mathbf{3 , 7}$ & $\mathbf{5 5 , 2}$ & $\mathbf{1 1 , 1}$ & $\mathbf{2 0 , 2}$ \\
\multicolumn{1}{c}{ CV \% } & & $\mathbf{1 , 8}$ & $\mathbf{1 1 , 8}$ & $\mathbf{1 2 , 0}$ & $\mathbf{2 8 , 7}$
\end{tabular}

${ }^{1}$ Matéria Seca (MS), pH, Fibra em Detergente Neutro (FDN); Proteína Bruta (PB) e Amido.

${ }^{2}$ Médias seguidas de mesma letra não diferem entre si pelo teste de Tukey a $5 \%$ de probabilidade.

Fonte: Próprios autores

$\mathrm{O} \mathrm{pH}$ das silagens diferiu estatisticamente apresentando valores variando entre de 3,6 a 3,8 nos genótipos avaliados (Tabela 5). Porém, todas as silagens apresentaram pH dentro dos limites estabelecidos para classificação de silagens de boa qualidade. $\mathrm{O}$ valor médio de $\mathrm{pH}$ observado nas silagens dos diferentes genótipos de milho foi de 3,7, sendo considerado de ótima qualidade, pois se encontra na faixa de $\mathrm{pH}$ de 3,6 a 4,5 recomendada por Nussio et al. (2001). Segundo D' Oliveira e Oliveira (2014), a baixo do pH é uma característica que define uma boa qualidade da silagem, conservando por um longo período de tempo suas propriedades nutricionais, pois atua inibindo ou controlando o desenvolvimento de microrganismos prejudiciais.

O teor de Fibra em Detergente Neutro (FDN) é indicativo da quantidade total de fibra do volumoso, estando diretamente relacionado ao consumo pelos animais. Os teores de FDN das silagens Revista Ifes Ciência, v.4, n.2, 2018 - Instituto Federal do Espírito Santo 
variaram entre 48,1 e 58,6\%, diferindo estatisticamente. D' Oliveira e Oliveira (2014), relatam que valores inferiores a 52\% são mais desejáveis. Quanto maior o teor de FDN, menor será a digestibilidade da planta. $\mathrm{O}$ menor teor de fibras pode ser obtido com materiais que possuem maior proporção de grãos na planta (maior diluição da porção FDN por amido). No entanto, deve-se ressaltar que a digestibilidade da FDN é determinada por componentes genético e ambientais. Em outras palavras, além da escolha do material genético adequado, as práticas agronômicas e de ensilagem exercem grande impacto sobre a qualidade da fibra da silagem de milho (DIAS JÚNIOR, 2016).

O teor de Proteína Bruta (PB) diferiu estatisticamente entre os genótipos avaliados (Tabela 5). A silagem obtida do genótipo Encapa apresentou o maior teor de PB $(12,6 \%)$ enquanto o menor teor de PB foi encontrado na silagem do genótipo Piranão 11 (10,4\%). O valor médio de PB obtidos das silagens dos diferentes genótipos de milho foi 11,1. Segundo Jaremtchuk et al. (2005), normalmente o teor de proteína bruta na silagem de milho varia entre 6\% e 9\%. Para D' Oliveira e Oliveira (2014), a cultivar de milho para a produção de uma silagem de boa qualidade deve ter entra $7 \%$ a 10\% de proteína bruta. Porém, Obeid et al. (2006), indicam que o índice ideal de proteína bruta contida na forragem para a alimentação de bovinos é de $12 \%$, valores abaixo destes devem ser suplementados com a adição de um concentrado para suprir as exigências nutricionais do rebanho.

Os teores de amido das silagens também diferiram significativamente entre os genótipos (Tabela 5), observando-se o maior teor para o Encapa (29,6\%) e o menor, para o Cimmyt (14,2\%). Segundo Henrique et al. (2007), o amido é o principal constituinte do milho, sendo responsável pela maior parte da energia presente na silagem com digestibilidade na maioria das vezes superior a $90 \%$.

\section{CONCLUSÃO}

As populações Piranão 14 e Cimmyt 14 são recomendadas para produção de silagem de milho de planta inteira devido a alta produtividade de grãos e número de espiga, além de possuírem porte baixo o que favorecendo a produção de silagem de melhor qualidade.

\section{REFERÊNCIAS}

AOAC. Official Methodsof Analysis. 19th ed. Assoc. Off. Anal. Chem. Arlington, VA. 2012

ALMEIDA FILHO, S.L. et al. Características agronômicas de cultivares de milho (Zea mays, L.) e qualidade dos componentes e silagem. Revista Brasileira de Zootecnia, Viçosa, v.28, n.1, p.7-13, 1999. 
BERILLI, A.P.C.G. et al. Use of molecular markers in reciprocal recurrent selection of maize increases heterosis effects. Genetics and Molecular Research, v.10, n.4, p.2589-2596, 2011.

BERILLI, A.P.C.G. et. al. Response to the selection in the 11th cycle of reciprocal recurrent selection among full-sib families of maize. Acta Scientiarum Agronomy, v.35, n.4, p.435-441, 2013.

BUSATO, C. C. M. Produção e qualidade da uva Niágara Rosada fertirrigada com diferentes doses de nitrogênio em Colatina, ES. Viçosa, 2010. 106 f. Tese (Doutorado em Engenharia Agrícola) - Universidade Federal de Viçosa, Viçosa, Viçosa, 2010.

CONAB. Acompanhamento da safra brasileira de grãos: Monitoramento agrícola - safra 2016/17: Décimo segundo levantamento. Setembro de 2017. Disponível em: <http://www.conab.gov.br>. Acesso em: 28 mar. 2018.

DAROS, M. et al. Correlações entre caracteres agronômicos em dois ciclos de seleção recorrente em milho-pipoca. Ciência Rural, v.34, n.5, p.1389-1394, 2004.

DIAS JÚNIOR, G. S. Seis pontos importantes na escolha de híbridos de milho para silagem. Revista Leite Integral. 2016. Disponível em: <http://www.revistaleiteintegral.com.br/noticia/seispontos-importantes-na-escolha-de-hibridos-de-milho-para-silagem>. Acesso em: 27 out. 2017.

D' OLIVEIRA, P. S.; OLIVEIRA, J. S. Produção de silagem de milho para suplementação do rebanho leiteiro. Juiz de Fora, MG: EMBRAPA, 2014. (Comunicado Técnico)

HALL, M. B. Determination of starch, including maltooligosaccharides, in animal feeds: comparison of methods and a method recommended for AOAC collaborative study. Journal of AOAC International, Arlington, v.92, n.1, p.42-49, 2009.

HENRIQUE, W. et al. Avaliação da silagem de grão de milho úmido com diferentes volumosos para tourinhos em terminação. Desempenho e características de carcaça. Revista Brasileira de Zootecnia, Viçosa, v.36, n.1, p.183-190, 2007.

Instituto Capixaba de Pesquisa, Assistência Técnica e Extensão Rural (INCAPER). Sistema de Informações Meteorológicas. Disponível em: <https://meteorologia.incaper.es.gov.br/estacoes-doano>. Acesso: 02 nov. 2017.

JAREMTCHUK, A.R. et al. Características agronômicas e bromatológicas de vinte genótipos de milho (Zea mays L.) para silagem na região leste paranaense. Acta Scientiarum Animal Sciences. Maringá, v.27, n.2, p.181-188, 2005.

LUPATINI, G. C. Avaliação do desempenho agronômico de híbridos de milho (Zea mays, L.) para produção de silagem. Revista Brasileira de Milho e Sorgo, Sete Lagoas, v.3, n.2, p.193-203, 2004.

NUSSIO, L.G. et al. Importância da qualidade da porção vegetativa no valor alimentício da silagem de milho. In: SIMPÓSIO SOBRE PRODUÇÃO E UTILIZAÇÃO DE FORRAGENS CONSERVADAS, Maringá. Anais... Maringá: UEM/CCA/DZO, 2001. 319 p.

NEUMANN, M.; LEÃO, G. F. M., COELHO, M. G.; FIGUEIRA, D. N.; SPADA, C. A.; PERUSSOLO, L. F. Aspectos produtivos, nutricionais e bioeconômicos de híbridos de milho para produção de silagem. Archivos de Zootecnia, Córdoba, v.66, n.253, p.51-58,2017. 
OBEID, J. A. et al. Níveis de proteína bruta em dietas para bovinos de corte: consumo, digestibilidade e desempenho produtivo. Revista Brasileira de Zootecnia, Viçosa, v.35, n.6, p.2434-2442, 2006.

PAZIANI, S. F. et al. Características agronômicas e bromatológicas de híbridos de milho para produção de silagem. Revista Brasileira de Zootecnia, Viçosa, v.38, n.3, p.411-417, 2009.

Plano Estratégico de Desenvolvimento da Agricultura: Novo PEDEAG 2007 - 2025. Secretaria do Estado da Agricultura, Abastecimento, Aquicultura e Pesca. Vitória: SEAG. 284 p. 2008.

PINTO, A. P. Avaliação de doze cultivares de milho (Zea mays L.) para silagem. Semina: Ciências Agrárias, Londrina, v.31, n.4, p.1071-1078, 2010.

REPKE, R. A. et al. Altura de planta, altura de inserção de espiga e número de plantas acamadas de cinco híbridos de milho. In: CONGRESSO NACIONAL DE MILHO E SORGO, 29., 2012, Águas de Lindóia. 2012. Anais... Águas de Lindóia: ABMS, 2012. p.1940-1943.

ROSA, J.R.P. et al. Avaliação do comportamento agronômico de plantas e valor nutritivo de silagem de diferentes híbridos de milho (Zea mays, L.). Revista Brasileira de Zootecnia, Viçosa, v.33, n.2, p. 302-312, 2004.

SANTOS, F.S. et al. Genetic gain prediction of the third recurrent selection cycle in a popcorn population. Acta Scientiarum Agronomy, Maringá, v.30, supl. spe, p.651-665, 2008.

SCAPIM, C.A. et al. Uma proposta de classificação dos coeficientes de variação para a cultura do milho. Pesquisa Agropecuária Brasileira, Brasília, v.30, n.5, p.683- 686, 1995.

Van SOEST, P.J. Methods for dietary fiber, neutral detergent fiber, and nonstarch polysaccharides in relation to animal nutrition. Journal of Dairy Science, Savoy, v.74, n.10, p.3583-3597, 1991.

VAN SOEST, P. J. Nutritional Ecologyof the Ruminant. 2 ed. New york: Cornell University Press. 476p. 1994.

VIEIRA, V. C.; MARTIN, T. N.; MENEZES, L. F. G.; ORTIZ, S.; BERTONCELLI, P. E STORCK, L. Caracterização bromatológica de silagens de milho de genótipos super precoce.

Ciência Rural, Santa Maria, v.43, n.11, p.1925-1931, 2013. 